\title{
Ultrasonic Sensing System for Detecting Mixture of Water and Sugar Adulteration in Honey
}

\author{
Mac Jacob Badal ${ }^{1}$, John Ryan Erico Ballesteros ${ }^{2}$, Curt John Berdonado ${ }^{3}$, Sherwin Jualo ${ }^{4}$, Glenn \\ Magwili ${ }^{5,+}$, Mary Ann Latina \\ ${ }^{6}$ School of Electrical, Electronics and Computer Engineering Mapúa University, Philippines
}

\begin{abstract}
Adulteration in honey may cause various complications in human health. This paper proposed an ultrasonic sensing system for detecting mixture of water and sugar adulteration in honey. The system used a simple ultrasonic sensor which is non-invasive compared to previous studies and procedures for adulteration detection. The system was calibrated with honey from Pampanga, Philippines, which were then tested in a laboratory for authenticity before deliberately adulterated for testing. The system is calibrated and optimized with honey samples from $0 \%$ adulteration to $40 \%$ adulteration with $10 \%$ interval. The gathered data was used to generate an equation to calculate the percent amount of adulteration in honey. The equation is $y=-1.3507 x$ +743.89 . The system accuracy obtained during actual testing which is $92.38 \%$. The system is delimited only to a specific variant of honey present in Pampanga.
\end{abstract}

.Keywords: Adulteration, honey, ultrasonic sensor

\section{Introduction}

Adulteration is the process of adding impurities to a pure substance. In food industry, adulterated or contaminated food can be considered as unsafe and unwholesome. Food contamination is categorized as one of the leading cause of diseases in the world. Several incidents have occurred regarding food contamination due to poor harvesting, storing, use of prohibited veterinary products, industrial discharges, human error, and deliberate adulteration. In 2014, the Food and Drug Administration in U.S.A. wanted to fight food contamination by giving support to food industries [1].

One of the common adulterated liquid products is honey and it takes several processes to detect whether it is adulterated or not. Liquid products, such as honey, are easily combined with impurities since it is very miscible in nature and because of its high demand. According to an article by Julian Wright, a British Agricultural Scientist, our national consumption of honey is unknown, but it must be estimated to about 1,000 tons per year.

Several studies were conducted which provides an information that an ultrasonic sensor could be used in detecting adulteration in fluid foods. One study [2] shows how ultrasonic waves propagate through adulterated liquids. The viscosity, density and other properties of the liquid affects the propagation delay of the ultrasonic waves travelling through it. The use of iodine to detect adulteration is common in honey which wastes samples due to its irreversible contamination. A study [3] showed the use of a traditional method to determine the adulteration in milk and finds that the method contaminates the milk. One study [4] made use of ELISA which is an enzyme-linked immunosorbent assay and is capable of detecting Immunoglobulin present in milk. The method is effective however, the Immunoglobulin that the ELISA detects is not present in honey. Another system was designed to determine the adulteration in milk, however the adulterants that the researcher used was only water [5]. Current means in detection uses contact sensors or chemicals which

\footnotetext{
+ Corresponding author. Tel.: + 6322475000; fax: +6323366088 .

E-mail address: gvmagwili@mapua.edu.ph.
} 
harms the honey and turns the sample into wastes. Present detection devices like e-tongue [6] are costly which suppress the mass production of it.

The general objective of this paper is to develop an ultrasonic sensing system for detecting mixture of water and sugar adulteration in honey. Specific objectives for this study are: (1) to create a prototype that receives a sample that will be scanned by sensors and produce an output that will display adulteration level of honey in percentage on the LCD module, (2) to characterize samples, and (3) to test the system for detecting the percent adulteration of honey.

The study will provide a better, less destructive way of detecting adulteration of honey. It will benefit the producers and the distributors to provide pure honey and lessen adulterated products passing through quality control. It is limited to the prediction of the level of adulteration in honey with water and sugar mixture. This study considered only a single supply of honey and is only limited to that specific type of honey. If the sample came from a different supplier, a recalibration is necessary.

\section{Methodology}

The design flowchart, Figure 1, discusses the main process of how the system. Initially, (1) the honey will be placed below the prototype and will act as the main input of the system. (2) The ultrasonic sensor determines the time of propagation of the wave. (3) The wave from the ultrasonic sensor will be received after passing through the honey. (4) The data gathered by the ultrasonic sensor, will be used in correlation with the equation uploaded to the microcontroller to compute the percent adulteration. (5) The computed adulteration in percent is displayed in the LCD module. Specifically, the LCD will display the text "Adulteration: (value of adulteration in percent)". If no honey is poured in the Honey Box, The LCD will display "No Honey".

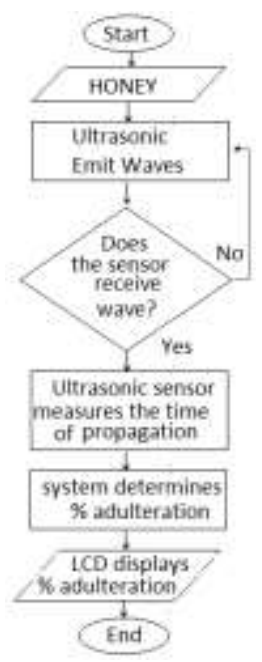

Fig. 1: Research Flowchart.

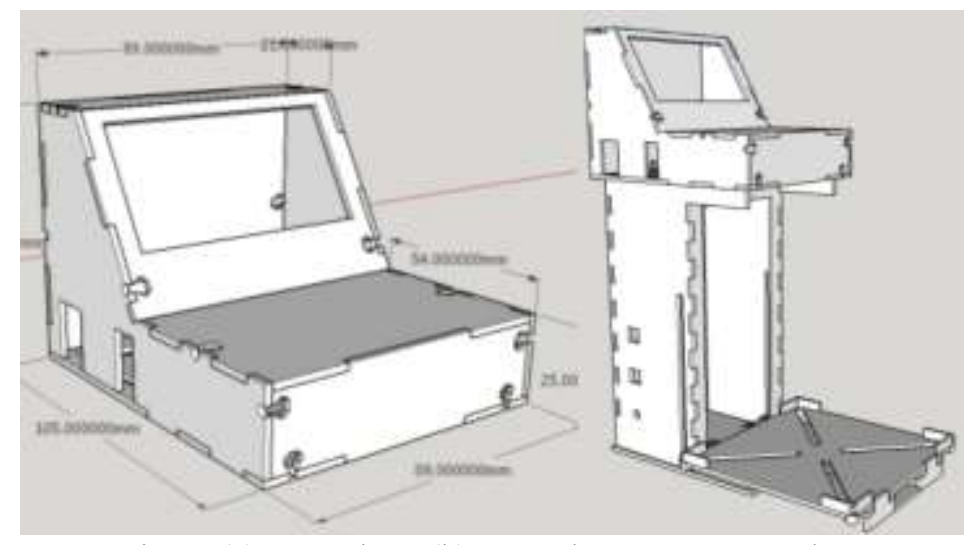

Fig. 2: (a) Honeybox (b) Honeybox + Mount enclosure 


\subsection{Hardware Design}

Figure 2 (a) is a SketchUp design for the prototype. The figure shows the dimensions of the Honeybox. It houses the Arduino microcontroller, the ultrasonic sensor and the LCD module. Figure 2 (b) lower part is a lift enclosure which will be used to change the distance between the ultrasonic sensor and the honey sample during optimization and testing. The lift will be in a fixed position after determining the optimized container and distance during the process. Figure 2 (b) shows the two individual enclosures assembled together.

\subsection{Preparation of the Adulterated Honey Samples}

In the preparation of the water and sugar mixture, a $1 \mathrm{~kg}$ brown sugar and $2 \mathrm{~L}$ of water was mixed together. To create a proper mixture, the sugar was boiled first. At boiling point, the sugar is added to the water whilst continuously stirred.

According to the honey provider in Pampanga, the honey adulteration is done by adding $10 \mathrm{~mL}$ of water and sugar mixture to $90 \mathrm{~mL}$ pure honey to produce a $100 \mathrm{~mL} 10$ percent adulterated honey, $20 \mathrm{~mL}$ sugar and water mixture to $80 \mathrm{~mL}$ pure honey for 20 percent adulterated honey and so on. The researchers have used 0 percent (pure honey) to 40 percent adulterated honey for calibration and testing. A sample batch of the adulterated honey with their respective adulteration level indicated that adulteration levels that are higher than $40 \%$ are too light colored which can be an early indication of adulteration and less viscous too.

\subsection{Characterization of Honey}

The parameters in characterization are the time of ultrasonic wave propagation and percent adulteration. The signal's speed of propagation depends on its medium"s density which are air and the honey in which it will affect the time needed for each propagation because of different honey densities. The relationship of the parameters will be expressed in an equation that will act as the backbone of the system 's algorithm. Also, the second batch of the honey samples obtained from the same supplier, undergone laboratory testing to determine the authenticity of the honey. The results provided positive results suggesting that the honey samples we obtained from Pampanga are genuine and pure.

\subsection{Gathering the Time of Propagation of the Wave with Respective Per cent Adulteration}

Five trials for each percent adulteration was conducted and the samples will be from a single source to avoid distinct densities between $100 \%$ pure honey samples. The time of propagation for each percent adulteration was obtained and was used to plot a graph.

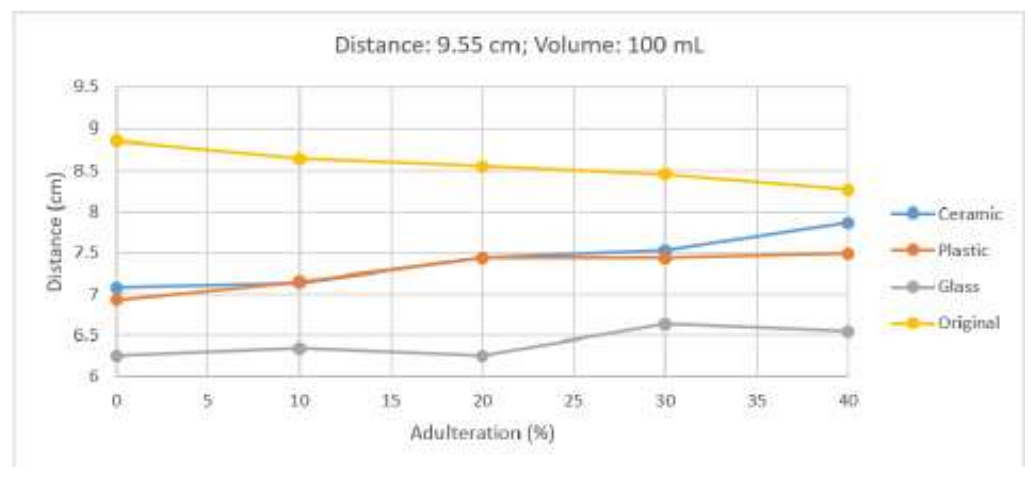

Fig. 3: Results of various materials with distance of $9.55 \mathrm{~cm}$ and volume of $100 \mathrm{~mL}$

To optimize the values being read by the prototype, the material used for the container of the honey are varied, along with the height of the sensor form the honey, the depth of the honey, the volume of the samples, and the diameter of each containers. Other than these factors, the honey samples were also prepared, each for different adulteration levels in percent from $0 \%$ to $40 \%$ with intervals of $10 \%$.

Table 1 shows the data gathered during the first phase of the optimization. These are the values read by the system in centimeters, indicating the distance between the sensor and the honey sample contained in 
these containers. During the optimization process, the factors were interchanged to determine the best results under certain conditions. For the first phase, the system was tested under these conditions:

- Constant distance between the ultrasonic sensor and honey samples of $9.55 \mathrm{~cm}$

- Constant volume of $100 \mathrm{~mL}$ for each sample with different adulterations

Table 1: Distance Optimization Table

\begin{tabular}{|c|c|c|c|c|c|c|c|c|}
\hline $\begin{array}{l}\text { Volume: } \\
100 \mathrm{~mL}\end{array}$ & $\begin{array}{l}\text { Distance } \\
9.55 \mathrm{~cm}\end{array}$ & & & & & & & \\
\hline Material & $\begin{array}{l}\text { Diameter } \\
\qquad(\mathrm{cm})\end{array}$ & $\begin{array}{l}\text { Height } \\
(\mathrm{cm})\end{array}$ & $\begin{array}{l}\text { Depth } \\
\text { (cm) }\end{array}$ & $\begin{array}{c}\text { Distance } \\
\text { (cm) } \\
@ 0 \%\end{array}$ & $\begin{array}{c}\text { Distance } \\
\text { (cm) } \\
\text { @10\% }\end{array}$ & $\begin{array}{c}\text { Distance } \\
\text { (cm) } \\
@ 20 \%\end{array}$ & $\begin{array}{c}\text { Distance } \\
\text { (cm) } \\
@ 30 \%\end{array}$ & $\begin{array}{c}\text { Distance } \\
\text { (cm) } \\
\text { @ } 40 \%\end{array}$ \\
\hline Ceramic & $\begin{array}{l}7.8 \mathrm{~cm} \\
\text { (inner) }\end{array}$ & $4.1 \mathrm{~cm}$ & $2.5 \mathrm{~cm}$ & $\begin{array}{c}7.08-7.19 \\
\mathrm{~cm}\end{array}$ & $\begin{array}{c}7.14-7.25 \\
\mathrm{~cm}\end{array}$ & $\begin{array}{c}7.44-7.54 \\
\mathrm{~cm}\end{array}$ & $\begin{array}{c}7.53-7.97 \\
\mathrm{~cm}\end{array}$ & $\begin{array}{c}7.87-7.97 \\
\mathrm{~cm}\end{array}$ \\
\hline Plastic & $7.2 \mathrm{~cm}$ & $\begin{array}{l}10.1 \\
\mathrm{~cm}\end{array}$ & $2.5 \mathrm{~cm}$ & $\begin{array}{c}6.93-7.03 \\
\mathrm{~cm}\end{array}$ & $\begin{array}{c}7.15-7.25 \\
\mathrm{~cm}\end{array}$ & $\begin{array}{c}7.44-7.54 \\
\mathrm{~cm}\end{array}$ & $\begin{array}{c}7.44-7.54 \\
\mathrm{~cm}\end{array}$ & $\begin{array}{c}7.49-7.85 \\
\mathrm{~cm}\end{array}$ \\
\hline Glass & $6.8 \mathrm{~cm}$ & $7.8 \mathrm{~cm}$ & $2.5 \mathrm{~cm}$ & $\begin{array}{c}6.25-6.35 \\
\mathrm{~cm}\end{array}$ & $\begin{array}{c}6.34 \cdot 6.44 \\
\mathrm{~cm}\end{array}$ & $\begin{array}{c}6.25-6.35 \\
\mathrm{~cm}\end{array}$ & $\begin{array}{c}6.63-6.74 \\
\mathrm{~cm}\end{array}$ & $\begin{array}{c}6.54-6.66 \\
\mathrm{~cm}\end{array}$ \\
\hline Original & $11.3 \mathrm{~cm}$ & $3.6 \mathrm{~cm}$ & $0.9 \mathrm{~cm}$ & $\begin{array}{c}8.87-8.97 \\
\mathrm{~cm}\end{array}$ & $\begin{array}{c}8.65-8.75 \\
\mathrm{~cm}\end{array}$ & $\begin{array}{c}8.56-8.68 \\
\mathrm{~cm}\end{array}$ & $\begin{array}{c}8.46-8.56 \\
\mathrm{~cm}\end{array}$ & $\begin{array}{c}8.27-8.38 \\
\mathrm{~cm}\end{array}$ \\
\hline
\end{tabular}

The first phase of the optimization procedure yielded the graph in Figure 3. OGC- „Original Container", was the original plastic container the samples were stored in after being deliberately adulterated for testing purposes. The container yielded the best trend among the other containers.

Table 2: Honeybox+Mount Actual Output Table

\begin{tabular}{|c|c|c|c|c|c|c|}
\hline \%Adulteration & $\begin{array}{c}\text { Time } \\
\text { ( } \mu \mathrm{s})\end{array}$ & Trial 1 & Trial 2 & Trial 3 & Trial 4 & Mean \\
\hline $0 \%$ & $550 \mu \mathrm{s}$ & $551 \mu \mathrm{s}$ & $550 \mu \mathrm{s}$ & $551 \mu \mathrm{s}$ & $551 \mu \mathrm{s}$ & $550.6 \mu \mathrm{s}$ \\
\hline $10 \%$ & $543 \mu \mathrm{s}$ & $547 \mu \mathrm{s}$ & $540 \mu \mathrm{s}$ & $546 \mu \mathrm{s}$ & $544 \mu \mathrm{s}$ & $544 \mu \mathrm{s}$ \\
\hline $20 \%$ & $533 \mu \mathrm{s}$ & $539 \mu \mathrm{s}$ & $533 \mu \mathrm{s}$ & $539 \mu \mathrm{s}$ & $533 \mu \mathrm{s}$ & $535.4 \mu \mathrm{s}$ \\
\hline $30 \%$ & $522 \mu \mathrm{s}$ & $539 \mu \mathrm{s}$ & $525 \mu \mathrm{s}$ & $533 \mu \mathrm{s}$ & $520 \mu \mathrm{s}$ & $527.8 \mu \mathrm{s}$ \\
\hline $40 \%$ & $516 \mu \mathrm{s}$ & $522 \mu \mathrm{s}$ & $521 \mu \mathrm{s}$ & $528 \mu \mathrm{s}$ & $522 \mu \mathrm{s}$ & $521.8 \mu \mathrm{s}$ \\
\hline
\end{tabular}

Table 2 contains the results obtained during actual testing with the Honeybox prototype mounted on the lift enclosure. The actual $\%$ adulteration was compared to the time of propagation to correlate the desired output of experimental \% adulteration to the raw readings of the ultrasonic sensor, decreasing errors and round ups of values. The extrapolation of the data in linear was then used as the basis of the final formula that the whole system will use in determining the adulteration level of a sample.

Using the average time of propagation in table 2, the data are extrapolated to generate an equation. The researcher generated linear, 2nd order polynomial, 3rd order polynomial and logarithmic equations to determine the proper equation. The linear equation provided constant values. The equation proves to be the best to represent the data gathered. The final system equation is as follows: $y=-1.3507 x+743.89$

Where: $\mathrm{y}$ - Percent Adulteration (\%) and $\mathrm{x}$ - Time of Propagation ( $\mu \mathrm{s})$.

Table 3: Average Percent Accuracy of the System

\begin{tabular}{|c|c|c|}
\hline $\begin{array}{c}\text { Actual Percent } \\
\text { Adulteration }\end{array}$ & $\begin{array}{c}\text { Oberved Percent Adulteration } \\
\text { (Average of 5 trials) }\end{array}$ & $\begin{array}{c}\text { Percent } \\
\text { Accuracy (\%) }\end{array}$ \\
\hline $0 \%$ & $0.20 \%$ & 80.00 \\
\hline $10 \%$ & $9.11 \%$ & 91.09 \\
\hline $20 \%$ & $20.73 \%$ & 96.38 \\
\hline $30 \%$ & $30.99 \%$ & 96.70 \\
\hline $40 \%$ & $39.10 \%$ & 97.74 \\
\hline Average & & 92.38 \\
\hline
\end{tabular}

Table 3 shows the result of the actual vs observed percent adulteration in honey. For each sample of $0 \%$, $10 \%, 20 \%, 30 \%, 40 \%$, the actual percentage has been compared for each trial of these percentage adulteration. All percent adulteration has the $t$ statistics value that is less than the $t$ critical two tail value which indicates that the result of each trial (actual vs observed) has no significant difference, thus accepting the hypothesis. The percent accuracy of the system was found to be $7.62 \%$ by averaging all the percent accuracy of each percent adulteration (5 Trials). 
Table 4 shows the results when commercially available honeys are tested using the system. The test was under optimized parameters-each has a volume of $100 \mathrm{~mL}$, a vertical distance of $9.55 \mathrm{~cm}$, and "Original ${ }^{\text {ee }}$ container were used. The "Cem"s Prime Brand Honey" and "MERRYLAND Honey", based on their ingredients, are adulterated with inverted syrup. Inverted syrups are a combination of fructose and glucose.

Table 4: Actual System Readings with Selected Commercial Honey
\begin{tabular}{|c|c|c|c|}
\hline Actual & $\begin{array}{c}\text { Capilano Pure } \\
\text { Australian Honey }\end{array}$ & $\begin{array}{c}\text { Cem's Prime Brand } \\
\text { Honey }\end{array}$ & $\begin{array}{c}\text { MERRYLAND } \\
\text { Honey }\end{array}$ \\
\hline Irial 1 & $0.34 \%$ & $25.62 \%$ & $29.98 \%$ \\
\hline Irial 2 & $0.7 \%$ & $25.25 \%$ & $27.44 \%$ \\
\hline Irial 3 & $0.02 \%$ & $26.71 \%$ & $32.17 \%$ \\
\hline Trial 4 & $2.89 \%$ & $27.8 \%$ & $29.26 \%$ \\
\hline Trial 5 & $1.84 \%$ & $24.89 \%$ & $29.98 \%$ \\
\hline
\end{tabular}

\section{Conclusion}

An ultrasonic sensing system was developed to detect the level of adulteration present in honey when a water and sugar mixture adulterant is present. The Honey Box is designed and created to accept honey samples which will be detected by an ultrasonic sensor. The system displays the detected adulteration in percent in the LCD module connected. The research was able to characterize the samples from $0 \%$ adulteration to $40 \%$ adulteration with intervals of 10 .

The total system accuracy is equal to the average percent accuracy of the system which is equal to 92.38\% This was the output using the linear equation: $y=-1.3507 x+743.89$. Optimization procedures considered factors such as sensor distance from the samples, container material, sample volume, and container dimensions. The system is not accurate in detecting the exact percent adulteration present in the honey, however the system is able to determine whether the sample is adulterated or not.

\section{Acknowledgements}

The researchers would like to acknowledge the following people who contributed in fulfilling each and every objective of this research. To the panels members and also the ECE subject chair Engr. Marloun Sejera for guiding the researchers.

\section{References}

[1] Y.Tahara, K.Toko, “Electronic Tongues - A Review”, In IEEE Sensors Journal, Vol. 13, No. 8, August, 2013

[2] L.A Dias, A.M Peres, A.C.A Veloso, F.S. Reis, M. Vilas-Boas, A.A.S.C. Machado, “An Electronic tongue taste evaluation: Identification of goat milk adulteration with bovine milk”, In Sensors and Actuators B..., 2009

[3] L.Nuñez, X.Cetó, M.I.Pividori, M.V.B.Zanoni, M. del Valle, "Development and application of an electronic tongue for detection and monitoring of nitrate, nitrite, and ammonium levels in waters", In Microchemical Journal 110 (2013), pp. 273 - 279, 25 April 2013

[4] N. Bidin, N.H. Zainuddin, S. Islam, M. Abdullah, F.M. Marsin, M. Yasin, "Sugar Detection in Adulterated Honey via Fiber Optic Displacement Sensor for Food Industrial Applications”, In IEEE Sensors Journal (Volume: 16, Issue: 2), pp. 299 - 305, 16 September 2015

[5] L. Mehryar, M. Esmaiili, "Honey \& Honey Adulteration Detecrion: A Review”, Department of Food Science and Technology, University of Urmia, Iran, 2013

[6] M.C.De Belen, F.RG.Cruz. , ,Water Quality Parameter Correlation in a Controlled Aquaculture Environment ${ }^{\text {eeee }}$ In 2017IEEE 9th International Conference on (HNICEM), 2017 